\title{
Assessment and Psycho-Social Intervention Process in Alcoholism
}

\section{* Manisha Chandra}

\section{Abstract}

Alcohol addiction is a complex and multi-dimensional problem. It has both medical and social ramifications which not only impacts individual but also his environment. The aim of this paper is to know how to take the history of the patient, assessment and intervention process to alleviate the client's alcohol addiction and to decrease malfunctioning in the person and his/her system which further enhances the client's satisfaction and self realization. The role of psychiatric social worker in assessment and intervention with substance abuse problem with individual and family and the effectiveness in improving of the individual and family functionality.

Key words: Assessment, Psycho social intervention, Alcoholism, social worker

\section{Introduction}

Alcohol abuse and addiction is one of our most challenging public health problems faced by any country. The magnitude of problem can be varying from time to time or person to person. In recent years, alcohol dependence has become a major social and personal menace in most societies. The mental and neurological conditions cause a significant amount of morbidity all over the world. It is estimated that about 450 million people are affected by mental, neurological and substance-abuse disorders (WHO, 2001). It is estimated that the burden of disease from neuropsychiatric conditions measured by DALY's will increase from 9 percent of the total disease burden in 1990 to 14 percent in 2020 (WHO, 2001). Worldwide, about two billion people consume alcoholic beverages and over 75 million are diagnosed with alcohol use disorders (WHO, 2001).

Alcohol use disorders accounted for 1.4 percent of the global disease

* Psychiatric Social Worker \& Research Scholar, Deptt. of Social Work, University of Delhi 
burden and its consumption is the leading risk factor for disease burden in low mortality low income countries (WHO, 2003). In the late 1990s it was estimated that 4.2 percent of the global population aged 15 and over used illicit drugs, causing 0.8 percent of the total burden of disability (WHO, 2003). Alcohol as a risk factor causes 4.0 percent of the total burden of disability and 3.2 percent of deaths (WHO, 2004).

In India, use of alcohol is from ancient times as inscripted in mythological texts. With recent development and changes, many new problems emerge in societies. Previously, alcohol use was occasional and had ritualistic connotations; people usually used it during major social events only but this drinking pattern has changed dramatically over the time (Mohan et al, 2001).

Over 20 percent of all disability-adjusted life years are lost chiefly because of factors like poor health status of the people and marked nutritional deficiencies as well as high prevalence of alcohol addiction among the people (Chakravarthy, 1990).In northern India, the 1-year prevalence of alcohol use has been estimated as 25 to 40 percent in the general population, whereas in southern India this rate has been estimated as 30to 50 percent. In southern India, the prevalence of alcohol use is higher among people of lower socioeconomic status and those who have lower levels of education (Peters et al, 2002; Chakravarthy, 1990). A large-scalesurvey over 32,000 people performed in 2001 found alcohol use rates of 20 to 38 percent in males and 10 percent among females. (Mohan et al, 2001).

\section{Therapeutic Framework: Bio-Psycho-Social-Spiritual Model}

This model has four components: biological, psychological, social and spiritual. It interrelates and bridges the disease model of alcoholism and psychological theories of learning and social patterns and spirituality with religiosity. The model presents possible pathways for practitioners to conceptualize alcohol and drug abuse as an interaction of individual factors and other factors. These pathways can also be described as nature and environmental factors that complement factors which are related to nurture. Its help in the assessment and treatment process through risk and protective 
factors.(Leukefeld \& Leukefeld 1999)

Figure: Possible pathways to alcohol and drug misuse (Leukefeld \& Leukefeld 1999

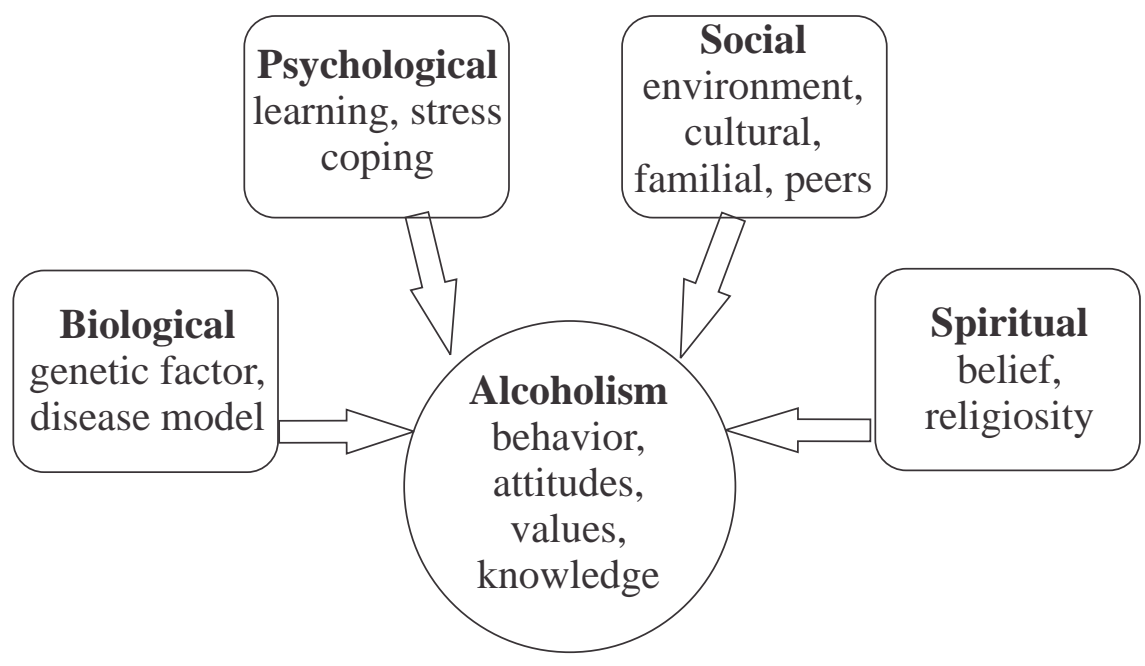

\section{Conceptual model}

The conceptual models introduced by Miller and Hester (2003), that state ambiguity, gravity of problem, dialectical interactions \& its significance in causes, characteristics \& treatment course of disorder. The studies have been done in various areas by numerous researchers which show various factors which are related to the alcoholism (rick or protective factor) as

- Inherent biochemical abnormalities (Blum \& Payne, 1991; Milam \& Ketcham, 1981)

- Genetic influence (Begleiter \& Kissin, 1995)

- Conflicted emotions (Denzin, 1993)

- Irrational cognitions (Ellis \& Velten, 1992)

- Social learning processes(Orford, 1985; Peele, 1985

- Socio-cultural influences (Cahalan, 1987; Edwards et al., 1994; Holder, 1998)

- Self-regulation failure (Baumeister, Heatherton, \& Tice, 1994) 
- And personal choice(Fingarette, 1988)

- Family pathology (Curtis, 1999; Steiner,1971; Steinglass, Bennett,Wolin, \& Reiss, 1987)

(Cited in Maltzman, 2008)

\section{Assessment Process in Substance Abuse Patient}

A proper assessment is necessary for treatment of the patient. It is not a one-time phenomenon but carried out at various stages. There are three stages of assessment as follows:

- Pre-intervention:- here the purpose of assessment is to define the problem; formulate treatment, select an appropriate treatment from various modalities and motivate clients for treatment

- Intervention:- here assessment is done to monitor progress

- Post-intervention:- assess maintenance and abstinence status

The assessment can be for various reasons was given below and done by trained mental health professionals (psychiatrists, psychiatric social worker, clinical psychologists)

- Brief screening for treatment purpose

- Basic assessment to diagnosis

- Reassessment for continuing care Tools of assessment

- Clinical history: intake history, mental status examination

- Investigation: physical examination, laboratory tests

- Questionnaires/scales: structured assessment such as CAGE, MAST, DAST, AUDIT

\section{Intake History: Basic Framework}

1. Patient's socio-demographic profile includes name, age, sex, marital status, qualification, occupation, type of family and members in family, religion, caste, economic background etc.

2. Details of drug use or taking which includes as follows

- At which age initiation started

- What types of various drugs used

- How frequently are drugs used 
- The quantity of drug taken usually (usual-dose)

- The last time lag since the dose used

- Is there need to increase the quantity of drug consumed in order to produce the same effect (tolerance)

- Is there any effect due to the use of a particular drug and signs and symptoms of intoxication

- The presence/ absence of physiological/psychological symptoms and signs when particular drug is not taken/ less than the usual amount of drug is being taken (withdrawals)

- Is there compelling need/ urge to take the sub-stance (craving)

3. Complications associated with drug use should be inquired. This can be in various spheres of patients' life $\&$ his/her environment and gives the treating team, areas to be focused during rehabilitation. The areas probed are

- $\quad$ Physical: long term health hazards associated with drug use ( cirrhosis, fatty liver, head injury, fetal alcohol syndrome, wenicke-korsakaffs syndrome)

- Psychological: chronic mental effects of continuous use of drug(depressant)

- Financial: losses suffered/debts incurred

- Occupational: frequent absenteeism at work, constant change of job, memos issued, periods of unemployment

- Familial-social: frequent fight with spouse/ other family members, neglect of responsibility at home, social outcast, peer pressure

- Legal: involvement in illegal activities to sustain drug use, arrests/ charges on ac-count of drug use, caught driving under intoxicated state, drinking brawl.

- High risk behaviours: presence of injection use with needle sharing and unsafe sexual practices

4. Past abstinence attempts: Here, an inquiry should be made regarding number of attempts made, duration of each attempt, 
reason for abstinence, whether treatment sought or not, nature of treatment sought: pharmacological, psychological or combined, reason for relapse. The information collected would be very helpful in deciding further treatment plan and measures to be taken to prevent relapses

5. Reason for seeking treatment and motivational level of individual: whether seeking treatment by self or brought forcibly by family member. Assessing level of motivation would help the clinician decide the type of intervention needed.

6. Psychiatric illnesses such as a mood disorder, psychotic disorder and personality disorder/ traits are common co morbid conditions accompanying substance use disorder. Presence of co morbid psychiatric illness should be specifically inquired and intervention modified accordingly.

7. Presence of family history of drug use, psychiatric illness and the current living arrangements. Extent of social support should be assessed. Pre-morbid personality: especially presence/absence of antisocial personality disorder. (Lal, 2005)

After taking clinical history from the patient and informants (parents, spouse, or other relatives) and medical examination and test conducted, diagnosis is made by mental health professional using ICD-10 guidelines. The reliability and validity of information play important role in the intervention plan has to formulate according to patients need.

\section{Intervention Process in Substance Abuse Patient}

In treatment and intervention process both pharmacological and nonpharmacological aspects play the role. The combination of both the methods yields most favourable treatment outcome. The pharmacological treatment is done by psychiatrists and nonpharmacological interventions are plan by psychiatric social worker and clinical psychologists with a team-work.

\section{Psychosocial Intervention}

Psychosocial approach is one of the basic and effective treatment approaches in dealing the person with mental illness. It is widely used 
in psychiatric and other social setting. It assesses the overall psychosocial aspect of the client's problem which includes both psychological and social factors. Psychological problems often have roots in socio-cultural practices which may lead to trigger stressors in addiction. It is very important to study a case in the context of his /her environment in order to draw clues of illness/ problem and help in treatment process. It includes behavior therapy, cognitive therapy, counseling, motivational therapy, relapse prevention theory problem solving therapy, family \& marital therapy, social self groups, vocational rehabilitation, peer support services, community based treatment. The intervention can used as one of them or in combination for effective treatment of patient.

Goals of intervention can be classified as

- Immediate goals:- completion of detoxification, intervention in psycho-social and medical crisis

- Short-team goals:-management of medical and psychiatric co-mobility, reduce the risks behaviour related to drugs use, reintegration of family

- Long -term goals:- prevention of relapse, reintegration into society, occupational rehabailition and improvement in overall quality of life

Interventions can be delivered in a variety of settings such as outpatient or inpatient clinics, mental health private practitioners, primary care clinics, schools, hospitals, community settings and virtual settings such as telephone and video conferencing. And it can occur in different formats such as individual or groups and can be administered by a variety of providers from psychiatric social workers, psychiatrists, and psychologists as professional to family members, peer group, religious leadersor community providers as social supportive member.

Each approach in psycho-social intervention has different theoretical concepts such as

- Behavioural approaches are based on the premise that excessive drinking is a learned habit and therefore influenced by principles of behaviour. The latter can, hence, be used to teach the individual a different behavioural pattern that will 
reduce the harm emerging from excessive drinking (NCCMH, 2011). Habits, reinforcement and punishment are components used for enhancing appropriate behavior in person.

- Cognitive approaches emphasise the role of thinking and cognition either prior to engaging in drinking behaviour or to prevent or avoid lapse or relapse (NCCMH, 2011). Minimization, rationalization and denial are most used defense mechanisms by the alcoholic abuse persons. Therefore proper way of thinking has to be imparted.

- Social approaches focus the work on the social environment, for example families or wider social networks (NCCMH, 2011)

- Motivational enhancement therapy based upon the willing component. These steps through which a person is motivated for change so that he is ready, willing and able (Prochaska \& DiClemente \& Miller cited in Lal, 2005)

- Psycho-education is about imparting knowledge related to the disorder, its causes, prognosis, stress factors, rick \&preventive measures, healthy living habits, importance of family \& social support in treatment process.

- Self help approach emphasised upon the uniting of people with similar problems to form a group for mutual help such as Alcoholic Anonymous (AA) (Lal, 2005)

- Family and marital therapy deals with the involvement and motivation of family member in the treatment process of the patient help in stabilizing the environment through managing change, proper reinforcement pattern, good communication pattern and reintegration of unit.

- Social correctional approach states that alcohol and drug abuse habits are considered as social deviance therefore the residential programmers are offered as a correctional method to the addicts such as therapeutic community (TC) (Lal, 2005) 


\section{Case Illustration}

Psychosocial Diagnosis: Index patient S.S.(name changed) is 20 years Hindu, unmarried male, educated up to 12th std. hailing from an urban area. Present complaints are increased in intake of alcohol; disobeying elders; restlessness; Decrease in sleep and appetite for the last one month. After taking clinical history and diagnosis made by professional, the case is referred to psychiatric social worker (PSW) for psychosocial intervention.

In Family assessment, the patient's family is nuclear family with semi permeable boundaries, with adequate reinforcement pattern and adequate social support because they all lives together and shares, the family atmosphere is uncongenial. Patient's elder sister is concerned regarding his illness and treatment. There is bad impact of illness on mother's mental health and social interaction is found. Communication pattern in the family is limited and unclear. But due to the illness family atmosphere is also being disturbed. Faulty reinforcement pattern, Faulty parenting, over involvement of the mother, maladaptive behavior patterns, and family structure are the some main psychosocial findings in the case. Overall assessment shows that patient lacks the basic amenities in his life, Manipulative behavior and inadequate friends circle of the patient. The impact of illness present in the family in forms of mild to moderate burden in the family routine activities, family leisure and mental health of others. Mild level of stigma is also lying the illness seriously affected the studies, social networks, motivation, happiness, leisure activity and behavior of the patient.

Then psychosocial management plan is made according to patient and family need.

- Establishing Rapport and Assess the Problem \& Development of therapeutic relationship.

- Psycho education with patient and family

- Supportive Case work

- School and vocational guidance

- $\mathrm{MET} \& \mathrm{RPT}$ 
- Parental counseling, reduce stigma, burden and expressed emotion

- Pre-discharge counseling

- Follow-up

\section{References}

Chakravarthy C (1990). Community workers estimate of drinking and alcohol related problems in rural areas. Indian Journal Psychological Medicine, 13, 49-56.

Lal, R. (2005) Substance Use Disorder-Manual for Physicians. National Drugs Dependence Treatment Centre, AIIMS. New Delhi

Leukefeld, C. G. \&Leukefeld, S. (1999) Primary Socialization Theory and a Bio/Psycho/Social/Spiritual Practice Model for Substance Use. Substance Use \& Misuse, 34(7), 983-991.

Maltzman, I. (2008) Alcoholism: Its Treatment \& Mistreatments. World Scientific Publishing Co.Pte.Ltd. Singapore

Miller, W. R. (1995) Motivational Enhancement Therapy for Drug Abusers. Alberquerque: CASS.

Mohan D, Chopra A, Ray R, Sethi H (2001). Alcohol consumption in India: A cross-sectional study. In: Room R, Demers A, Bourgault C, editors. Surveys of drinking patterns and problems in seven developing countries. Geneva: World Health Organization; 103-114.

National Collaborating Centre for Mental Health (NCCMH) (2011) Alcohol Use Disorders-The Nice Guideline on Diagnosis, Assessment and Management of Harmful Drinking and Alcohol Dependence. The British Psychological Society \&The Royal College of Psychiatrists. Great Britain

Peters DH, Preker AS, Yazbek AS, Sharma RR (2002). Better health systems for India's poor: findings analysis and options. Washington DC: The World Bank.

Singh, N.K., Bhattacharjee, D., Das, B., Kumar, M. (2009) Interaction Patterns in Indian Families with Alcohol-dependent Persons. Hong Kong Journal of Psychiatry, 19, 117-120.

World Health Organisation (1992) International Classification of Disease, 10 edition revision, Diagnostic Criteria for Research. Geneva.

World Health Organisation (2001). The World Health Report 2001. 
Mental Health: New Understanding, New Hope. WHO, Geneva, Switzerland.

World Health Organisation (2003). The World Health Report. WHO, Geneva, Switzerland.

World Health Organisation (2004). Global status report: Alcohol policy: World Health Organization. Department of Mental Health and Substance Abuse. Geneva, WHO, Switzerland.

World Health Organisation International Consortium of Psychiatric Epidemiology (2000). Cross-national comparisons of mental disorders. Bulletin of the World Health Organization, 78, 413-426.

World Health Organization (2001). Mental health resources in the world. Initial results of Project Atlas. Fact Sheet No. 260, April 2001, Geneva, Switzerland 